\title{
Potassium Concentration on Admission Is an Independent Risk Factor for Target Lesion Revascularization in Acute Myocardial Infarction
}

\author{
Tsuyoshi Honda, Kazuteru Fujimoto, Yuji Miyao, Hidenobu Koga, and Masanobu Ishii \\ Department of Cardiology, Cardiovascular Center, National Hospital Organization Kumamoto Medical Center, 1-5 Ninomaru, \\ Chuo-ku, Kumamoto 860-0008, Japan
}

Correspondence should be addressed to Tsuyoshi Honda; thonda@kumamoto2.hosp.go.jp

Received 6 August 2013; Accepted 22 October 2013; Published 12 January 2014

Academic Editors: D. G. Karalis, I. Misumi, P. Quax, and F. Thuny

Copyright (C) 2014 Tsuyoshi Honda et al. This is an open access article distributed under the Creative Commons Attribution License, which permits unrestricted use, distribution, and reproduction in any medium, provided the original work is properly cited.

\begin{abstract}
Background. Acute myocardial infarction (AMI) is accompanied by excessive production of catecholamines, which is characterized by a hypokalemic dip. A polymorphism of the adrenergic receptor has also been reported to be associated with target lesion revascularization (TLR) after coronary intervention. Subjects and Methods. We enrolled 276 consecutive patients with AMI within 24 hours of symptom onset, who underwent emergency coronary intervention using bare metal stents and had examinations over a 5-10-month follow-up period. The patients were divided into tertiles based on their serum potassium level on admission (low $\mathrm{K}$, $<3.9$; mid K, $\geq 3.9,<4.3$; and high $\mathrm{K}, \geq 4.3$ ). Results. Sixty-four TLRs were observed in the study. Increased potassium concentration was associated significantly with TLR. Patients in the high K group were about two and a half times more likely to have a TLR after AMI compared to those in the low K group. Multiple logistic analysis showed that potassium level on admission was an independent risk factor for TLR (odds ratio 1.69; confidence interval 1.04 to 2.74; $P=0.036$ ). Conclusions. These findings indicated that increased potassium levels on admission might predict TLRs in AMI patients treated with bare metal stents.
\end{abstract}

\section{Introduction}

Acute myocardial infarction (AMI) is a leading cause of death in adults, with AMI survivors having an increased risk of developing heart failure. It is important to evaluate patient risk such as cardiac remodeling and future adverse events in the early stage after an AMI.

Several pathological conditions are associated with sometimes marked increase in the plasma concentration of catecholamines. This increase is accompanied by hypokalemia [1]. The first well-documented example of this association was in a study of 14 patients with myocardial infarction (MI) [2]. A later study of 1074 patients with acute myocardial infarction (AMI) showed that hypokalemia correlated with ventricular fibrillation [3]. More recently, a study on 517 patients with MI showed that, at admission, only $8 \%$ had a low plasma $\mathrm{K}^{+}$, with these patients having a significantly higher frequency of ventricular fibrillation [4]. A prospective study on 2428 patients showed that acute coronary syndrome in patients treated with beta blockers was not associated with an early hypokalemic dip seen at the onset of chest pain. This indicated that the hypokalemia was a response to adrenergic activation of the $\mathrm{Na}^{+}, \mathrm{K}^{+}$pump. Interestingly, in patients with diabetes, the early hypokalemic dip was also shown to be absent, possibly reflecting sympathetic nerve dysfunction, a common complication of diabetes [5]. Attenuation is seen most clearly in unstable angina and is less pronounced in AMI when the early dip in potassium and its later recovery are preserved, albeit with a loss of significance [5]. This may reflect the fact that adrenergic responses to acute coronary syndromes are related to the extent of myocardial injury and are therefore greater in this condition [6]. However, the early dip in serum potassium concentrations has been shown to be attenuated when adrenergic stimulation of sodiumpotassium ATPase is blocked, thereby reducing potassium flux across the cell membrane. A previous study also demonstrated that $\beta_{2}$-adrenoceptors mediate the stimulating effect of adrenaline on active electrogenic $\mathrm{Na}-\mathrm{K}$ transport [7].

Previous studies have shown that a genetic inflammatory factor, the $\beta_{2}$-adrenergic receptor gene (ADRB2), predicts 
TABLE 1: Clinical characteristics of the patients at baseline.

\begin{tabular}{|c|c|c|c|c|}
\hline & $\begin{array}{c}\text { Low K }(<3.9) \\
\quad n=92\end{array}$ & $\begin{array}{c}\text { Mid K }(\geq 3.9,<4.3) \\
n=92\end{array}$ & $\begin{array}{c}\text { High } \mathrm{K}(\geq 4.3) \\
\quad n=92\end{array}$ & $P$ value \\
\hline Age (yrs) & $66 \pm 12$ & $67 \pm 13$ & $70 \pm 12^{*}$ & \\
\hline Male (\%) & $65(70.7)$ & $68(73.9)$ & $63(68.5)$ & 0.716 \\
\hline BMI (\%) & $23.8 \pm 2.8$ & $23.1 \pm 2.9$ & $23.6 \pm 3.5$ & \\
\hline Current smoker (\%) & $39(42.4)$ & $34(37.0)$ & $35(38.0)$ & 0.727 \\
\hline Hypertension (\%) & $63(68.5)$ & $48(52.2)$ & $56(60.9)$ & 0.0771 \\
\hline Diabetes mellitus (\%) & $24(26.1)$ & $29(31.5)$ & $38(41.3)$ & 0.0841 \\
\hline $\mathrm{T}-\mathrm{C}(\mathrm{mg} / \mathrm{dL})$ & $198 \pm 38$ & $195 \pm 39$ & $184 \pm 39^{*}$ & \\
\hline HDL-C (mg/dL) & $44 \pm 11$ & $45 \pm 12$ & $45 \pm 12$ & \\
\hline LDL-C (mg/dL) & $130 \pm 34$ & $126 \pm 32$ & $116 \pm 33^{* \dagger}$ & \\
\hline $\mathrm{TG}(\mathrm{mg} / \mathrm{dL})$ & $129 \pm 84$ & $124 \pm 76$ & $126 \pm 93$ & \\
\hline HbAlc (\%) & $6.0 \pm 1.7$ & $5.9 \pm 1.3$ & $6.3 \pm 1.5$ & \\
\hline \multicolumn{5}{|c|}{ Previous medical treatment } \\
\hline ACE-I/ARB (\%) & $17(18.5)$ & $21(22.8)$ & $24(26.1)$ & 0.581 \\
\hline Beta-blocker (\%) & $1(1.09)$ & $2(2.17)$ & $6(6.52)$ & 0.105 \\
\hline Diuretics (\%) & $4(4.35)$ & $3(3.26)$ & $7(7.61)$ & 0.411 \\
\hline Statin $(\%)$ & $13(14.1)$ & $14(15.2)$ & $18(19.6)$ & 0.573 \\
\hline
\end{tabular}

BMI: body mass index; T-C: total cholesterol; HDL-C: high-density lipoprotein cholesterol; LDL-C: low-density lipoprotein cholesterol; TG: triglyceride; HbAlc: hemoglobin Alc; ACE-I: angiotensin converting enzyme inhibitor; ARB: angiotensin receptor blocker. ${ }^{*} P<0.05$ versus low $\mathrm{K}$; $P<0.05$ versus mid $\mathrm{K}$.

restenosis after percutaneous coronary intervention [8]. The ADRB2 gene has a role in the inflammatory response, with adrenergic receptors on human platelets stimulating ADRB2 to activate platelet nitric oxide synthase (NOS) [9]. NOS catalyzes the formation of NO, which has an inhibitory role on leukocyte adhesion, platelet adhesion and aggregation, smooth muscle cell proliferation, and matrix proteins, and it also has an effect on promoting endothelial survival and proliferation [10].

This study examined the association between plasma potassium concentration on admission and target lesion revascularization in patients with AMI.

\section{Methods}

2.1. Study Population. We retrospectively studied 306 consecutive patients who underwent percutaneous coronary intervention (PCI) at Kumamoto Medical Center within 24 hours after the onset of AMI between January 2008 and October 2012 and had a follow-up examination 5 to 10 months later (Table 1). The diagnosis of AMI was made using the universal definition of myocardial infarction [11]. As differences in PCI (thrombolysis, aspiration, plain old balloon angioplasty (POBA), bare metal stents (BMSs), and drug-eluting stent (DES)) may influence TLR in patients with AMI, 30 patients were excluded from the study (1 for thrombolysis, 1 for aspiration, and 28 for DES) [12, 13]. The main exclusion criteria were the presence of malignant disease, severe renal failure, known hepatic disease, and the lack of a follow-up examination. The primary endpoint was TLR after AMI.

The patients were divided into tertiles according to potassium level on admission (low $\mathrm{K},<3.9$; mid $\mathrm{K}, \geq 3.9,<4.3$; and high $\mathrm{K}, \geq 4.3$ ).
Systolic blood pressure (SBP), heart rate (HR), plasma glucose (PG), white blood cell (WBC) count, creatinine, hemoglobin, and potassium were measured at the time of arrival at the Emergency Unit of Kumamoto Medical Center. Creatine kinase (CK) was measured every 4 to 6 hours after admission, and peak CK was calculated in all the patients. Blood samples for measurement of PG, WBC count, creatinine, hemoglobin, and potassium were obtained at the time of hospital admission. Total cholesterol (T-C), high-density lipoprotein cholesterol (HDL-C), low-density lipoprotein cholesterol (LDL-C), triglyceride (TG), and hemoglobin Alc (HbAlc) were measured in the fasting state on the day after admission.

2.2. Analysis of Coronary Risk Factors for Coronary Artery Disease. The traditional risk factors for coronary artery disease used in the statistical analyses were hypertension, lipid profiles (T-C, HDL-C, LDL-C, and TG), current cigarette smoking habits, body mass index (BMI), and diabetes mellitus. Current cigarette smoking was defined as $\geq 10$ cigarettes/day for 10 years including cessation of smoking within 1 year, hypertension as blood pressure $\geq 140 / 90 \mathrm{~mm} \mathrm{Hg}$ and/or the use of antihypertensive medication, and diabetes mellitus as a fasting blood glucose $\geq 126 \mathrm{mg} / \mathrm{dL}$ and/or HbAlc $\geq 6.5 \%$ or the use of antidiabetic medication.

2.3. Coronary Angiography and Coronary Intervention. Emergency coronary intervention using BMSs was performed in all the patients. The AMI sites were divided into two groups (anterior AMI and nonanterior AMI). A diseased coronary artery was defined as stenosis $\geq 75 \%$, with the patients being divided into two groups (single-vessel disease and multivessel disease). Reperfusion therapy was used at the discretion of the attending physician. 
TABLE 2: Clinical and angiographic characteristics of acute myocardial infarction.

\begin{tabular}{|c|c|c|c|c|}
\hline & $\begin{array}{c}\text { Low } \mathrm{K}(<3.9) \\
\qquad n=92\end{array}$ & $\begin{array}{c}\text { Mid K }(\geq 3.9,<4.3) \\
n=92\end{array}$ & $\begin{array}{c}\text { High } \mathrm{K}(\geq 4.3) \\
\quad n=92\end{array}$ & $P$ value \\
\hline Time from chest pain to door (hr) & $3.9 \pm 5.4$ & $5.2 \pm 6.4$ & $6.8 \pm 6.9^{*}$ & \\
\hline SBP on admission $(\mathrm{mmHg})$ & $133 \pm 30$ & $137 \pm 31$ & $131 \pm 35$ & \\
\hline HR on admission (mmHg) & $74 \pm 20$ & $74 \pm 19$ & $79 \pm 27$ & \\
\hline Previous MI & $4(4.35)$ & $7(7.61)$ & $9(9.78)$ & 0.359 \\
\hline Preinfarction angina & $36(39.1)$ & $36(39.1)$ & $25(27.2)$ & 0.146 \\
\hline STEMI & $73(79.3)$ & $70(76.0)$ & $61(66.3)$ & 0.111 \\
\hline Anterior MI & $50(54.3)$ & $42(45.7)$ & $41(44.6)$ & 0.347 \\
\hline Killip > I & $17(18.5)$ & $13(14.1)$ & $27(29.3)$ & 0.0318 \\
\hline Coronary multivessel involvement (\%) & $35(38.0)$ & $33(35.9)$ & $36(39.1)$ & 0.898 \\
\hline PG on admission (mg/dL) & $184 \pm 84$ & $169 \pm 65$ & $202 \pm 114^{\dagger}$ & \\
\hline WBC count on admission $\left(/ \mathrm{mm}^{3}\right)$ & $10685 \pm 3383$ & $9468 \pm 3412^{*}$ & $9998 \pm 3477$ & \\
\hline Creatinine on admission (mg/dL) & $0.79 \pm 0.59$ & $0.81 \pm 0.33$ & $0.99 \pm 0.90^{*}$ & \\
\hline Hemoglobin on admission (g/dL) & $14.0 \pm 1.6$ & $13.8 \pm 2.1$ & $13.6 \pm 2.2$ & \\
\hline Potassium on admission $(\mathrm{mEq} / \mathrm{L})$ & $3.6 \pm 0.2$ & $4.0 \pm 0.1^{*}$ & $4.7 \pm 0.6^{* \dagger}$ & \\
\hline Stent diameter implanted in culprit lesion (mm) & $3.17 \pm 0.44$ & $2.99 \pm 0.41^{*}$ & $2.92 \pm 0.44^{*}$ & \\
\hline Stent length implanted in culprit lesion (mm) & $22 \pm 9$ & $26 \pm 16$ & $22 \pm 9$ & \\
\hline TIMI grade 3 after PCI & $76(82.6)$ & $73(79.3)$ & $74(80.4)$ & 0.849 \\
\hline Peak CK & $3168 \pm 2755$ & $2322 \pm 2035^{*}$ & $2585 \pm 3080$ & \\
\hline
\end{tabular}

SBP: systolic blood pressure; HR: heart rate; MI: myocardial infarction; STEMI: ST-elevation myocardial infarction; PG: plasma glucose; WBC: white blood cell; TIMI: thrombolysis in myocardial infarction; PCI: percutaneous coronary intervention; CK: creatine phosphokinase. ${ }^{*} P<0.05$ versus low K; ${ }^{\dagger} P<0.05$ versus mid $\mathrm{K}$.

\subsection{Target Lesion Revascularization. A clinically driven TLR} procedure was defined as one performed because of recurrent angina and/or documented ischemia on noninvasive tests, with $>70 \%$ diameter stenosis assessed by quantitative coronary angiography (QCA) in the absence of symptoms [14].

2.5. Statistical Analysis. The subjects were divided into tertiles based on their serum potassium level on admission. Differences in frequencies were analyzed using the chisquare method. A comparison of continuous variables in the three groups was performed using a one-way analysis of variance (ANOVA), followed by Scheffé's procedure to compare individual groups. Continuous variables were compared in the two groups using a two-tailed paired $t$-test. Odds ratios (OR) and 95\% confidence intervals (CI) for target lesion revascularization (TLR) were calculated using logistic regression analysis. Differences with a $P$ value $<0.05$ were considered statistically significant in all the analyses. Data were expressed as the mean $\pm \mathrm{SD}$.

\section{Results}

3.1. Clinical Characteristics of Patients at Baseline. The patients in the high $\mathrm{K}$ group were significantly older than those in the low K group. Although the value for LDL-C was lower in the high K group than in the other groups, there was no difference in the other coronary risk factors and previous medical treatment between the three groups (Table 1).

3.2. Clinical and Angiographic Characteristics of AMI. The time between chest pain and admission was longer in the high $\mathrm{K}$ group than in the low $\mathrm{K}$ group. The incidence of Killip $\geq \mathrm{II}$ was increased in the high $\mathrm{K}$ group. PG was increased in the high $\mathrm{K}$ group compared with the mid $\mathrm{K}$ group. WBC count and peak CK were higher in the low $\mathrm{K}$ group than in the mid $\mathrm{K}$ group. Stent diameter implanted in the culprit lesion was larger in the low $\mathrm{K}$ group than in the two other groups (Table 2).

3.3. Clinical Characteristics of Patients at Followup. Sixtyfour TLRs (23.2\%) were observed in the patient group in the present study. The incidence of TLR was increased in the high K group. There were no significant differences in lipid profile and active medical treatment at followup between the three groups (Table 3 ).

3.4. Logistic Analysis for the Risk of Target Lesion Revascularization. Multiple logistic analysis using the variables listed in Tables 1 and 2 showed that admission potassium level (odds ratio, 1.69; $P=0.0360$; confidence interval, 1.04 to 2.74 ) was the strongest independent risk factor for predicting TLR (Table 4).

3.5. Relationship between Admission Potassium Level and Target Lesion Revascularization. A higher potassium concentration was observed in patients with TLR. Patients in the high K group were two and a half times more likely to have a TLR compared with the low K group (Table 5).

\section{Discussion}

We report for the first time that increased potassium concentration on admission is associated significantly with TLR in patients with AMI. 
TABLE 3: Clinical characteristics of the patients at followup.

\begin{tabular}{lccc}
\hline & Low K $(<3.9)$ & Mid K $(\geq 3.9,<4.3)$ & High K $(\geq 4.3)$ \\
$n=92$ & $187 \pm 65$ \\
& $n=92$ & $206 \pm 77$ & $29(31.5)$ \\
Time from PCI to followup (day) & $196 \pm 53$ & $21(22.8)$ & $172 \pm 38$ \\
Target lesion revascularization (\%) & $14(15.2)$ & $168 \pm 29$ & $47 \pm 11$ \\
T-C at followup (mg/dL) & $175 \pm 40$ & $49 \pm 12$ & $100 \pm 33$ \\
HDL-C at followup (mg/dL) & $47 \pm 10$ & $94 \pm 25$ & $141 \pm 63$ \\
LDL-C at followup (mg/dL) & $102 \pm 37$ & $135 \pm 67$ & \\
TG at followup (mg/dL) & $148 \pm 104$ & & $92(100)$ \\
Active medical treatment & & $91(98.9)$ & $71(77.2)$ \\
Aspirin & $92(100)$ & $81(88.0)$ & $33(35.9)$ \\
ACE-I/ARB & $79(85.9)$ & $29(31.5)$ & $26(28.3)$ \\
Beta-blocker & $27(29.3)$ & $27(29.3)$ & 0.367 \\
CaCB & $29(31.5)$ & $16(17.4)$ & 0.108 \\
Nitrate & $16(17.4)$ & $12(13.0)$ & 0.629 \\
Diuretics & $14(15.2)$ & $67(72.8)$ & 0.886 \\
Statin & $71(77.2)$ & 0.558 \\
\hline
\end{tabular}

PCI: percutaneous coronary intervention; T-C: total cholesterol; HDL-C: high-density lipoprotein cholesterol; LDL-C: low-density lipoprotein cholesterol; TG: triglyceride; ACE-I: angiotensin converting enzyme inhibitor; ARB: angiotensin receptor blocker; CaCB: calcium channel blocker.

In high $\mathrm{K}$ group, the value of creatinine and the incidence of Killip >I were increased. Renal elimination is the main excretion route of potassium, with approximately $90 \%$ being excreted by the kidney. Impaired renal function therefore predisposes to the development of hyperkalemia [15]. In addition, sympathetic nervous system hyperactivity is observed in patients with renal injury, chronic kidney disease, and end-stage renal disease [16]. Sympathetic nerve system activation has been shown to have a proinflammatory and profibrotic effect on the heart and vasculature and contributes to hyperinsulinemia and insulin resistance $[16,17]$. These effects might be associated with TLR after AMI. As Killip class is an index of heart failure and cardiogenic shock after AMI, a high Killip class on admission may be associated with a reduction in cardiac output and subsequent low renal blood flow, which may, in turn, reduce renal function and increase serum potassium level $[15,18]$.

In addition, there was a tendency that the incidence of DM increased in high K group. A previous study reported that ACS patients with diabetes had significantly higher serum potassium concentrations and did not exhibit the early dip seen in nondiabetes. This may reflect sympathetic nerve dysfunction, a common complication of diabetes [5]. Insulin resistance may also have a role in preventing the early dip in serum potassium in diabetes by attenuating intracellular ionic flux in the early stages after onset of symptoms. However, the experimental findings of Brown and colleagues indicate that insulin does not contribute significantly to adrenergically induced changes in serum potassium [19]. Acute coronary syndrome provides a useful clinical model of adrenergic stress as it reflects many of the typical presenting features such as diaphoresis and tachycardia. Hypokalemia has also been attributed to adrenergic stress, and the finding of lower serum potassium concentrations in patients presenting very early after the onset of chest pain is well recognized. So, we excluded AMI patients over 24 hours after onset in the present study.

On the other hand, there was a long delay in presentation to hospital in the high $\mathrm{K}$ group compared with the low $\mathrm{K}$ group. Past studies reported that aging and DM might be associated with atypical symptoms in AMI and delay in presentation to hospital [20-23]. Older age and the incidence of DM in the high $\mathrm{K}$ group might affect the prolonged time from chest pain to admission.

Currently, available BMSs are considerably more effective than older types of BMSs [24]. There is evidence that deployment of a BMS in AMI patients with infarct-related arteries $\geq 3.5 \mathrm{~mm}$ is associated with low rates of TLR [25]. Several studies have shown that diabetes, renal insufficiency, and minimum stent area are risk factors for restenosis after a primary PCI in patients with an AMI [26-29]. Hyperkalemia in AMI might be a marker of increased TLR risk in patients with more extensive and diffuse atherosclerotic vascular disease.

Although focus has been paid to potassium concentrations associated with lethal arrhythmias and mortality after an AMI, the present study demonstrated that increased potassium concentrations on admission may be an independent risk factor for TLR after these events [30-32]. A previous study showed that the polymorphism in the ADRB2 gene after adjustment for other variables was a risk factor for restenosis, with the $16 \mathrm{~A} / \mathrm{G}$ polymorphism resulting in an amino acid change from glycine to arginine at position 16 (Arg16Gly) [6]. Patients with homozygosity for the 16Gly variant may have different functional responses to adrenergic stimulation, thereby possibly modulating cardiovascular and metabolic phenotypes. It has been reported that the 16Gly variant of ADRB2 is associated with faster agonist-induced downregulation of the receptor compared with the 16Arg variant [33]. The higher risk of restenosis may be related to 
TABLE 4: Logistic analysis for the risk of target lesion revascularization.

\begin{tabular}{|c|c|c|c|c|}
\hline & \multicolumn{2}{|c|}{ Univariate model } & \multicolumn{2}{|c|}{ Multivariate model } \\
\hline & OR $(95 \% \mathrm{CI})$ & $P$ & OR $(95 \% \mathrm{CI})$ & $P$ \\
\hline Age & $1.01(0.989-1.04)$ & 0.286 & - & - \\
\hline Male & $1.81(0.924-3.56)$ & 0.0838 & - & - \\
\hline BMI & $1.05(0.959-1.15)$ & 0.292 & - & - \\
\hline Current smoker & $1.18(0.669-2.08)$ & 0.568 & - & - \\
\hline Hypertension & $0.940(0.532-1.66)$ & 0.833 & - & - \\
\hline Diabetes mellitus & $1.69(0.948-3.00)$ & 0.0751 & - & - \\
\hline $\mathrm{T}-\mathrm{C}$ & $0.996(0.989-1.00)$ & 0.258 & - & - \\
\hline HDL-C & $0.985(0.960-1.01)$ & 0.249 & - & - \\
\hline LDL-C & $0.998(0.989-1.01)$ & 0.624 & - & - \\
\hline TG & $0.999(0.996-1.00)$ & 0.613 & - & - \\
\hline Hemoglobin Alc & $1.11(0.925-1.33)$ & 0.266 & - & - \\
\hline Time from onset to admission & $1.05(1.01-1.09)$ & 0.0162 & $1.04(0.997-1.09)$ & 0.0688 \\
\hline SBP on admission & $1.01(1.00-1.02)$ & 0.0430 & $1.01(1.00-1.02)$ & 0.0550 \\
\hline HR on admission & $1.01(0.994-1.02)$ & 0.353 & - & - \\
\hline Previous MI & $0.817(0.263-2.54)$ & 0.726 & - & - \\
\hline Preinfarction angina & $0.957(0.532-1.72)$ & 0.883 & - & - \\
\hline STEMI & $0.488(0.268-0.889)$ & 0.0190 & $0.625(0.330-1.18)$ & 0.148 \\
\hline Anterior MI & $1.19(0.681-2.09)$ & 0.538 & - & - \\
\hline Killip class $>$ I on admission & $0.749(0.362-1.55)$ & 0.436 & - & - \\
\hline Coronary multivessel involvement & $1.51(0.858-2.67)$ & 0.152 & - & - \\
\hline PG on admission & $1.00(0.997-1.00)$ & 0.948 & - & - \\
\hline WBC count on admission & $1.00(1.00-1.00)$ & 0.843 & - & - \\
\hline Creatinine on admission & $1.20(0.823-1.74)$ & 0.347 & - & - \\
\hline Hemoglobin on admission & $1.03(0.897-1.19)$ & 0.642 & - & - \\
\hline Potassium on admission & $1.75(1.10-2.79)$ & 0.0187 & $1.69(1.04-2.74)$ & 0.0360 \\
\hline Diameter of implanted stent & $0.517(0.306-15.5)$ & 0.0493 & $0.763(0.383-1.52)$ & 0.442 \\
\hline Length of implanted stent & $1.02(0.997-1.04)$ & 0.0978 & - & - \\
\hline TIMI grade 3 after PCI & $1.04(0.509-2.12)$ & 0.916 & - & - \\
\hline Peak CK & $1.00(1.00-1.00)$ & 0.363 & - & - \\
\hline
\end{tabular}

OR: odds ratio; CI: confidence interval; BMI: body mass index; T-C: total cholesterol; HDL-C: high-density lipoprotein cholesterol; LDL-C: low-density lipoprotein cholesterol; TG: triglyceride; SBP: systolic blood pressure; HR: heart rate; MI: myocardial infarction; STEMI: ST-elevation myocardial infarction; PG: plasma glucose; WBC: white blood cell; TIMI: thrombolysis in myocardial infarction; PCI: percutaneous coronary intervention; CK: creatine phosphokinase.

TABLE 5: Target lesion revascularization according to potassium level.

\begin{tabular}{lccc}
\hline & & \multicolumn{2}{c}{ Target lesion revascularization } \\
& $n(\%)$ & OR & $95 \%$ CI \\
\hline Low K $(<3.9)(n=92)$ & $14(15.2)$ & 1.00 & - \\
Mid K $(\geq 3.9,<4.3)(n=92)$ & $21(22.8)$ & 1.65 & - \\
High K $(\geq 4.3)(n=92)$ & $29(31.5)$ & 2.57 & $0.779-3.49$ \\
\hline
\end{tabular}

OR: odds ratio; CI: confidence interval.

less vasodilatation as a result of downregulation of the receptor containing 16Gly compared with the receptor containing 16 Arg. Moreover, downregulation of the ADRB2 could result in impaired inhibition of platelet aggregation [8]. Previous studies have reported that the ADRB2 polymorphism may be associated with diabetes, insulin resistance, hypertension, and chronic kidney disease and that subjects with the polymorphism had a high risk for coronary heart disease [34, 35].
It is possible that the ADRB2 polymorphism might prevent the early dip in serum potassium as a result of attenuating intracellular ionic flux early after AMI onset by attenuation of adrenergic stimulation of sodium-potassium ATPase, because a previous study showed that $\beta_{2}$-adrenoceptors mediated the stimulatory effect of adrenaline on active electrogenic Na-K transport [7]. Although we did not investigate the ADRB2 polymorphism in this study, it is possible that 
hyperkalemia on admission (absence of early potassium dip) in AMI patients may be related to TLR after AMI via absence of the ADRB2 pathway.

\section{Conclusions}

In conclusion, the potassium level on admission for an AMI is an independent risk factor for TLR in AMI patients treated with BMSs.

\section{Conflict of Interests}

The authors declare that there is no conflict of interests regarding the publication of this paper.

\section{References}

[1] T. Clausen, "Hormonal and pharmacological modification of plasma potassium homeostasis," Fundamental and Clinical Pharmacology, vol. 24, no. 5, pp. 595-605, 2010.

[2] R. P. Karlsberg, P. E. Cryer, and R. Roberts, "Serial plasma catecholamine response early in the course of clinical acute myocardial infarction: relationship to infarct extent and mortality," American Heart Journal, vol. 102, no. 1, pp. 24-29, 1981.

[3] J. E. Nordrehaug, "Malignant arrhythmia in relation to serum potassium in acute myocardial infarction," American Journal of Cardiology, vol. 56, no. 6, pp. 20D-23D, 1985.

[4] J. E. Madias, B. Shah, G. Chintalapally, G. Chalavarya, and N. E. Madias, "Admission serum potassium in patients with acute myocardial infarction: its correlates and value as a determinant of in-hospital outcome," Chest, vol. 118, no. 4, pp. 904-913, 2000.

[5] K. Foo, N. Sekhri, A. Deaner et al., "Effect of diabetes on serum potassium concentrations in acute coronary syndromes," Heart, vol. 89, no. 1, pp. 31-35, 2003.

[6] R. P. Karlsberg, P. E. Cryer, and R. Roberts, "Serial plasma catecholamine response early in the course of clinical acute myocardial infarction: relationship to infarct extent and mortality," American Heart Journal, vol. 102, no. 1, pp. 24-29, 1981.

[7] T. Clausen, "Adrenergic control of $\mathrm{Na}^{+}-\mathrm{K}^{+}$-homeostasis," Acta Medica Scandinavica. Supplementum, vol. 672, pp. 111-115, 1983.

[8] P. S. Monraats, N. M. M. Pires, W. R. P. Agema et al., "Genetic inflammatory factors predict restenosis after percutaneous coronary interventions," Circulation, vol. 112, no. 16, pp. 24172425, 2005.

[9] L. R. Queen, B. Xu, K. Horinouchi, I. Fisher, and A. Ferro, " $\beta 2$-adrenoceptors activate nitric oxide synthase in human platelets," Circulation Research, vol. 87, no. 1, pp. 39-44, 2000.

[10] A. F. Chen, J. Ren, and C.-Y. Miao, "Nitric oxide synthase gene therapy for cardiovascular disease," Japanese Journal of Pharmacology, vol. 89, no. 4, pp. 327-336, 2002.

[11] K. Thygesen, J. S. Alpert, and H. D. White, "Joint ESC/ACCF/AHA/WHF Task Force for the Redefinition of Myocardial Infarction. Universal definition of myocardial infarction," Circulation, vol. 116, pp. 2634-2653, 2007.

[12] E. Garcia-Cantu, C. Spaulding, T. Corcos et al., "Stent implantation in acute myocardial infarction," American Journal of Cardiology, vol. 77, no. 7, pp. 451-454, 1996.

[13] V. Pasceri, G. Patti, G. Speciale, C. Pristipino, G. Richichi, and G. Di Sciascio, "Meta-analysis of clinical trials on use of drugeluting stents for treatment of acute myocardial infarction," American Heart Journal, vol. 153, no. 5, pp. 749-754, 2007.
[14] E. Schampaert, E. A. Cohen, M. Schlüter et al., "The Canadian study of the sirolimus-eluting stent in the treatment of patients with long de novo lesions in small native coronary arteries (CSIRIUS)," Journal of the American College of Cardiology, vol. 43, no. 6, pp. 1110-1115, 2004.

[15] K. Takaichi, F. Takemoto, Y. Ubara, and Y. Mori, "Analysis of factors causing hyperkalemia," Internal Medicine, vol. 46, no. 12, pp. 823-829, 2007.

[16] K. Masuo, G. W. Lambert, M. D. Esler, H. Rakugi, T. Ogihara, and M. P. Schlaich, "The role of sympathetic nervous activity in renal injury and end-stage renal disease," Hypertension Research, vol. 33, no. 6, pp. 521-528, 2010.

[17] K. A. Jamerson, S. Julius, T. Gudbrandsson, O. Andersson, and D. O. Brant, "Reflex sympathetic activation induces acute insulin resistance in the human forearm," Hypertension, vol. 21, no. 5, pp. 618-623, 1993.

[18] P. G. Hsiao, C. A. Hsieh, C. F. Yeh et al., "Early prediction of acute kidney injury in patients with acute myocardial injury," Journal of Critical Care, vol. 525, pp. e1-e7, 2012.

[19] M. J. Brown, D. C. Brown, and M. B. Murphy, "Hypokalemia from beta2-receptor stimulation by circulating epinephrine," The New England Journal of Medicine, vol. 309, no. 23, pp. 14141419, 1983.

[20] C. G. Solomon, T. H. Lee, E. F. Cook et al., "Comparison of clinical presentation of acute myocardial infarction in patients older than 65 years of age to younger patients: The Multicenter Chest Pain Study Experience," American Journal of Cardiology, vol. 63, no. 12, pp. 772-776, 1989.

[21] V. Culić, D. Eterović, D. Mirić, and N. Silić, "Symptom presentation of acute myocardial infarction: influence of sex, age, and risk factors," American Heart Journal, vol. 144, pp. 1012-1017, 2002.

[22] S. A. Grossman, D. F. M. Brown, Y. Chang et al., "Predictors of delay in presentation to the ED in patients with suspected acute coronary syndromes," American Journal of Emergency Medicine, vol. 21, no. 5, pp. 425-428, 2003.

[23] K. K. Ho, S. W. Lee, S. B. S. Ooi, F. Lateef, S. H. Lim, and V. Anantharaman, "Acute coronary syndrome-factors causing delayed presentation at the Emergency Department," Annals of the Academy of Medicine Singapore, vol. 31, no. 3, pp. 387-392, 2002.

[24] H. Fujimoto, S. Tao, J. Masuda et al., "The efficacy of bare metal stent implantation for patients with acute myocardial infarction in the drug-eluting stent era," Journal of Cardiology, vol. 51, no. 3, pp. 189-195, 2008.

[25] I. M. Shugman, L. Hee, C. J. Mussap et al., "Bare-metal stenting of large coronary arteries in ST-elevation myocardial infarction is associated with low rates of target vessel revascularization," American Heart Journal, vol. 165, pp. 591-599, 2013.

[26] H. M. Sadeghi, G. W. Stone, C. L. Grines et al., "Impact of renal insufficiency in patients undergoing primary angioplasty for acute myocardial infarction," Circulation, vol. 108, no. 22, pp. 2769-2775, 2003.

[27] H. Okura, H. Taguchi, T. Kubo et al., "Impact of arterial remodelling and plaque rupture on target and non-target lesion revascularisation after stent implantation in patients with acute coronary syndrome: an intravascular ultrasound study," Heart, vol. 93, no. 10, pp. 1219-1225, 2007.

[28] E. Cristea, G. W. Stone, R. Mehran, A. J. Kirtane, and S. J. Brener, "Changes in reference vessel diameter in ST-segment elevation myocardial infarction after primary percutaneous coronary 
intervention: implications for appropriate stent sizing," American Heart Journal, vol. 162, no. 1, pp. 173-177, 2011.

[29] S.-Y. Choi, A. Maehara, E. Cristea et al., "Usefulness of minimum stent cross sectional area as a predictor of angiographic restenosis after primary percutaneous coronary intervention in acute myocardial infarction (from the HORIZONS-AMI Trial IVUS substudy)," American Journal of Cardiology, vol. 109, no. 4, pp. 455-460, 2012.

[30] J. E. Nordrehaug and G. Von Der Lippe, "Hypokalaemia and ventricular fibrillation in acute myocardial infarction," British Heart Journal, vol. 50, no. 6, pp. 525-529, 1983.

[31] J. E. Nordrehaug, K. A. Johannessen, and G. Von Der Lippe, "Serum potassium concentration as a risk factor of ventricular arrhythmias early in acute myocardial infarction," Circulation, vol. 71, no. 4, pp. 645-649, 1985.

[32] A. Goyal, J. A. Spertus, K. Gosch et al., "Serum potassium levels and mortality in acute myocardial infarction," The Journal of the American Medical Association, vol. 307, no. 2, pp. 157-164, 2012.

[33] B. D. Hoit, D. P. Suresh, L. Craft, R. A. Walsh, and S. B. Liggett, " $\beta 2$-Adrenergic receptor polymorphisms at amino acid 16 differentially influence agonist-stimulated blood pressure and peripheral blood flow in normal individuals," American Heart Journal, vol. 139, no. 3, pp. 537-542, 2000.

[34] K. Masuo, T. Katsuya, Y. Fu, H. Rakugi, T. Ogihara, and M. L. Tuck, " $\beta 2$-adrenoceptor polymorphisms relate to insulin resistance and sympathetic overactivity as early markers of metabolic disease in nonobese, normotensive individuals," American Journal of Hypertension, vol. 18, no. 7, pp. 1009-1014, 2005.

[35] Y. Chen, M. S. Lipkowitz, R. M. Salem et al., "Progression of chronic kidney disease: adrenergic genetic influence on glomerular filtration rate decline in hypertensive nephrosclerosis," American Journal of Nephrology, vol. 32, no. 1, pp. 23-30, 2010. 


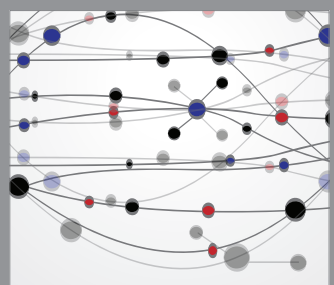

The Scientific World Journal
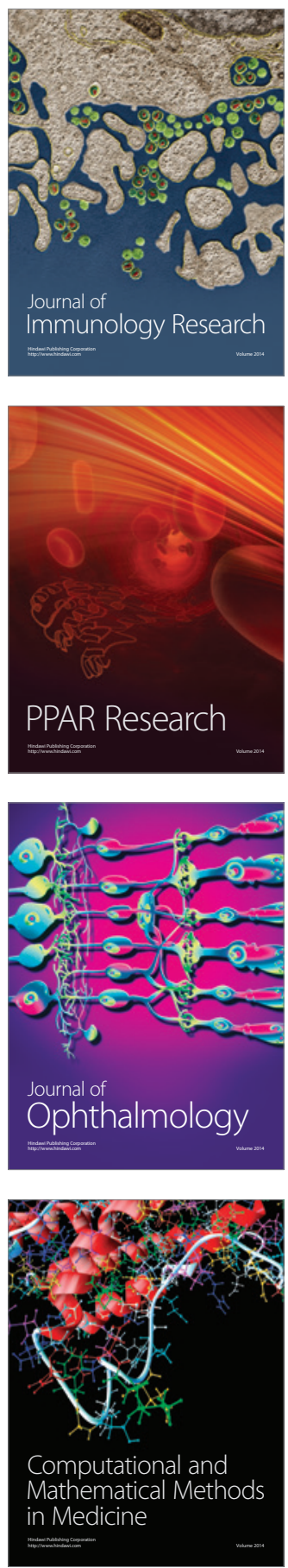

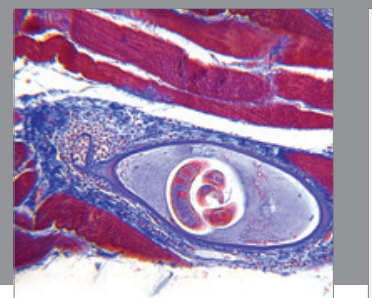

Gastroenterology

Research and Practice
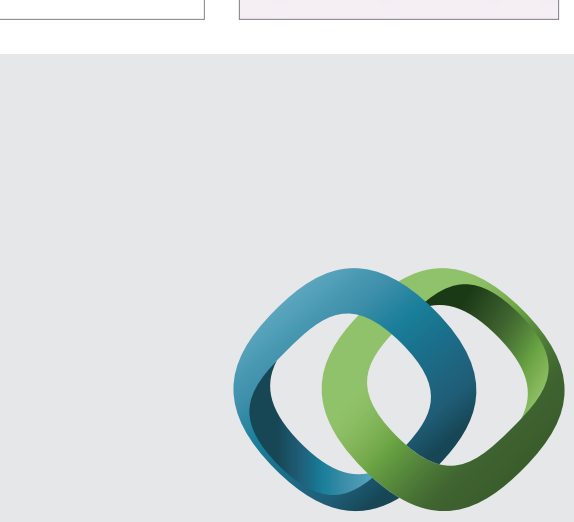

\section{Hindawi}

Submit your manuscripts at

http://www.hindawi.com
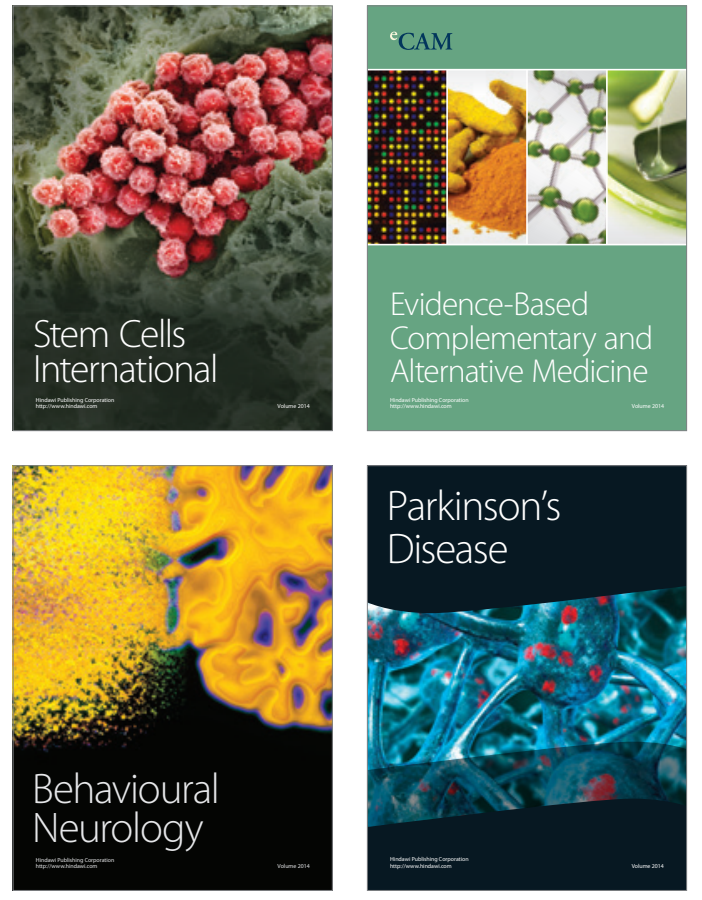
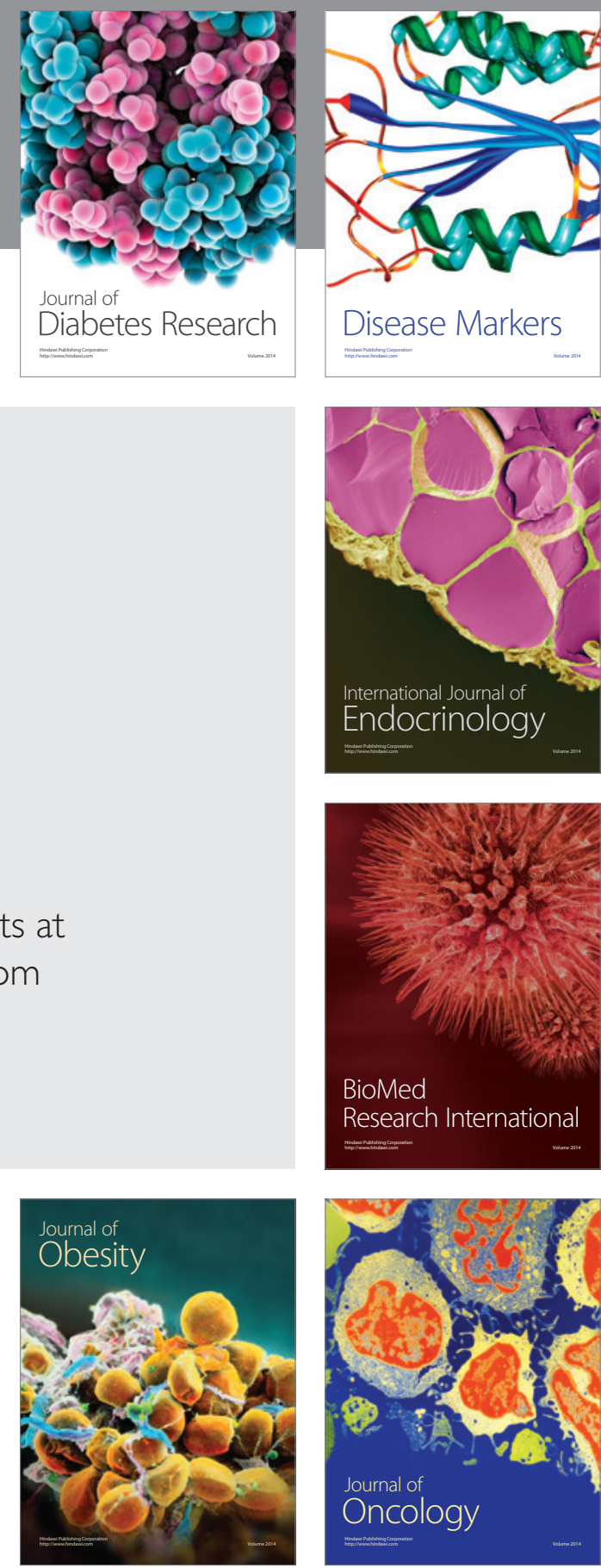

Disease Markers
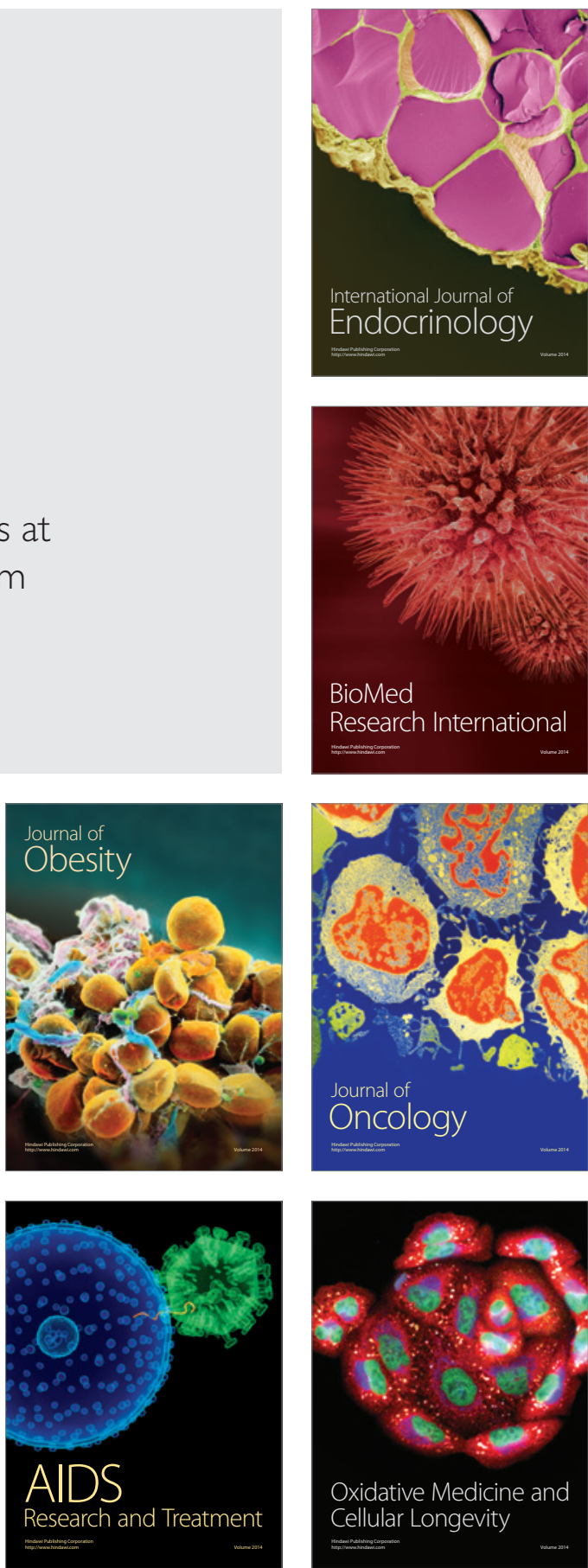